\title{
QUANTUM KEY DISTRIBUTION POLYGON
}

\author{
Ondřej Klíčník \\ Bachelor Degree Programme (3), FEEC BUT \\ E-mail: xklicn02@vutbr.cz \\ Supervised by: Petr Münster \\ E-mail: munster@feec.vutbr.cz
}

\begin{abstract}
This article presents basics of quantum key distribution BB84-like protocols. Briefly explains principles of their operations and impact of QBER on intrusion detection. Afterwards results of QKD simulations are presented as well as own QKD polygon draft (on multiplexed optical fibre).
\end{abstract}

Keywords: BB84, Quantum key distribution (QKD), QKD networks (QKDN), QKD polygons

\section{1 ÚVOD}

Pro přenos šifrovaných dat je nejdříve nutné ustanovit mezi dvěma uzly symetrický šifrovací klíč. V současných počítačových sítích slouží $\mathrm{k}$ tomuto účelu tzv. asymetrická kryptografie, založená na matematických problémech. Její algoritmy jsou však náchylné na útoky tzv. kvantových počítačů. Tedy technologii, která by dle odhadů mohla být v blízké době dostupná. $\mathrm{V}$ roce 1984 prrišla dvojice fyziků Gilles Brassard a Charles Bennett s novým způsobem ustanovení klíče, postaveném na jevech kvantové mechaniky. Tato metoda přenosu klíče se tak podle nich nazývá protokolem BB84. Ačkoliv dnes již existuje velké množství nejrůznějších protokolů založených na rozličných kvantových principech, BB84 zůstává stále jedním z nejpoužívanějších a existuje v bezpočtu modifikací. [1]

\section{RODINA PROTOKOLŮ BB84}

Původní verze protokolu je postavená na tzv. polarizačním kódování a počítá s ideálním zdrojem jednotlivých fotonů (SPS). Stručně lze protokol shrnout takto. BB84 využívá čtyř stavů polarizace, tedy dvou bází $\{|\uparrow\rangle,|\rightarrow|\}$ a $\{|\lambda\rangle,|\searrow\rangle\}$. Jak je možné vidět níže na obrázku 1 , jsou tyto báze na polarizátoru vzájemně pootočeny o $45^{\circ}$. Protokol začíná tím, že si Alice vygeneruje náhodný návrh klíče. Následně náhodně přepíná mezi bázemi a bitům tak přiděluje vybranou polarizaci fotonu. [1]
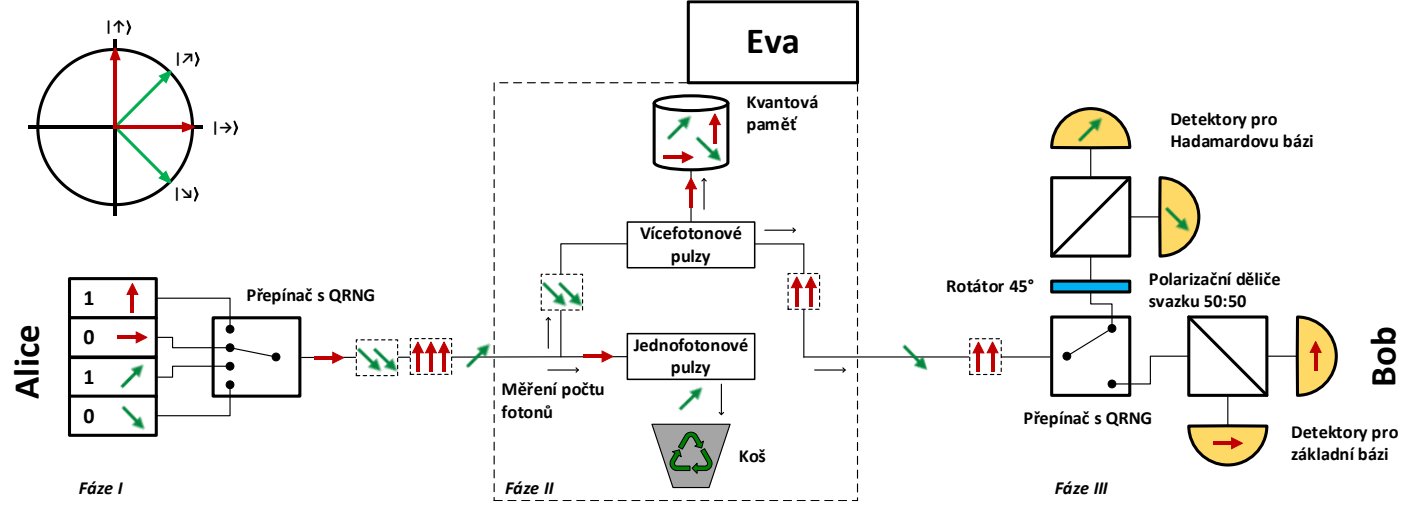

Obrázek 1: Schéma protokolu BB84 s odposlechem. [2]

Pro QKD protokoly je nutné využívat kvantového generování čísel (QRNG), to zaručuje distribuci 50:50 a pravou náhodnost. Fotony jsou optickým vláknem zaslány k Bobovi. Ten také náhodně volí báze. Pokud zvolí stejnou bázi jako Alice, je foton vždy správně rozklíčován. Pokud zvolí bázi opačnou, je foton rozklíčován v 50 \% prrípadů. Bob však v tuto chvíli netuší, které bity v jeho řetězci 
neodpovídají původním Aliciným hodnotám. Bob proto odešle Alici po libovolném kanálu pořadí použitých bází. Alice je porovná s vlastními bity. Ty, u kterých se báze shodují, prohlásí za surový klíč (raw key), ostatní bity zahodí. Bobovi pak pošle pořadí vhodných bitů. Tak získá klíč i Bob. [1]

Surový klíč však ještě nemusí být kvůli chybám zcela shodný. To může znamenat odposlech. K jeho detekci je tak potřeba klíč „prosít“. Z tohoto důvodu se část klíče zveřejní. Tím lze určit chybovost přenosu neboli QBER (Quantum-Bit Error Rate). Vysoké QBER je př́znakem odposlechu. Pokud by se zde totiž Eva vyskytovala, byla by nucena stavy fotonů měřit a volbou bází by sama dělala chyby. Ty by se následně projevily na QBER. V ideálním případě by jediným zdrojem chyb byla Eva. Kvůli nedokonalostem př́strojů ale vznikají chyby i jiným způsobem (zdroje, přenosová soustava, detektory). Z těchto důvodů je nízká chybovost tolerována (u BB84 do cca $11 \%$ ). [1]

V praxi se ovšem SPS nepoužívá a místo něj jsou nasazovány lasery se slabými koherentními pulzy (WCP). Pravděpodobnost odeslání jednoho fotonu je dána Poissonovým rozložením. Teoreticky tak může být současně odesláno fotonů i více. To je príležitostí pro Evu, která si může nadbytečný foton ponechat a zbytek poslat dál Bobovi. Jednofotonové pulzy zahodí. Jedná se o tzv. PNS útok a je rovněž zobrazen na obrázku 1 . K obraně proti němu slouží tzv. návnadové stavy (decoy states). [1]

Pro zvýšení dosahu lze však BB84 najít i s fázovým kódováním. Výraznou modifikací je pak protokol T12 (Toshiba 2012). Jedná se o efektivní variantu BB84, jenž většinou implementuje fázové kódování. Hlavním rozdílem je asymetrické používání bází. Tedy minoritní báze je vybrána např. ve $20 \%$ př́ípadů a majoritní báze v 80 \% př́padů. Tento poměr byl využit i v simulaci. [1]

\section{KVANTOVÁ BITOVÁ CHYBOVOST (QBER)}

Polygony všech tři výše zmíněných variant protokolu byly vymodelovány pomocí programu VPItransmissionMaker ${ }^{\mathrm{TM}}$ Optical Systems a knihovny VPItoolkit QKD. Simulace slouží k měření QBER, nejdůležitějšího parametru v QKD. QBER je vypočítávána v průběhu prosévání klíče. [3]

$$
Q B E R=\frac{v_{\text {chyby }}}{v_{\text {cíl }}}
$$

QBER- Kvantová bitová chybovost [-]

$v_{\text {chyby }}-$ Počet chyb za sekundu [bit/s]

$v_{\text {cil }}$ - Bitová (přenosová) rychlost u cíle [bit/s]

Hodnota QBER bývá u většiny QKD protokolů zásadní pro detekci odposlechu. To znamená, že Eva bude v ideálním případě (SPS) vytváŕet chybovost okolo $25 \%$. Za bezpečnou chybovost je u BB84 protokolů považována hranice $11 \%$. QBER rovna $50 \%$ znamená nulovou korelaci mezi Alicí a Bobem. Bobovy výsledky jsou tedy zcela náhodné a neodpovídají tomu, co Alice poslala. [3]

\section{SIMULACE QKD A MĚŘENÍ QBER}

\subsection{ZÁVISLOST QBER NA DÉLCE KVANTOVÉHO KANÁLU}

V reálném světě je QBER generována nejen Evou, ale i prodlužující se délkou kvantového kanálu (útlum). Obecné zapojení polygonů lze najít níže (pro daný protokol je vždy použit specifický vysílač a přijímač). Jedná se o WCP protokoly využívající návnadových stavů. Měrný útlum kvantového kanálu je nastaven na $\alpha=0,24 \mathrm{~dB} / \mathrm{km}$. S rostoucí délkou $l[\mathrm{~km}]$ tak dochází k postupnému zvýšení útlumu kanálu podle vzorce $a=\alpha l[d B]$. Čím je útlum kanálu vyšší, tím vyšší je i pravděpodobnost

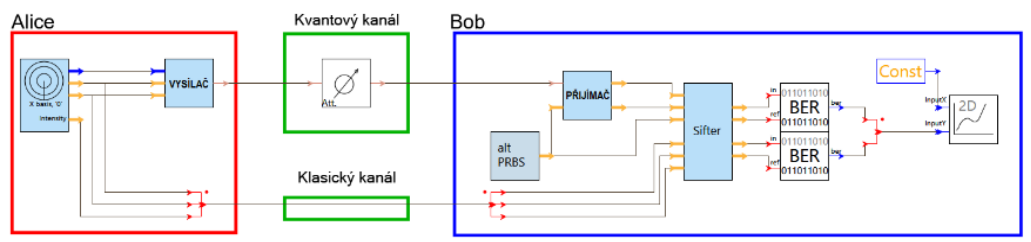

Obrázek 2: Obecné zapojení testovaných protokolů. 
falešné detekce fotonu (dark count). Délka kvantového kanálu s každou iterací simulace roste o $5 \mathrm{~km}$. Celkem je tak měření provedeno 23 krát pro vzdálenosti od 0 do $110 \mathrm{~km}$. Chybovost př́strojů byla taktéž změřena a osciluje kolem $1 \%$.

\subsection{VÝSLEDKY}

Výsledné grafy popisují závislost QBER na délce kvantového kanálu, a tedy i na útlumu. Hodnoty QBER pro vybrané délky jsou zapsány $\mathrm{v}$ tabulce. Výsledky měření odpovídají tvrzení, že fázové kódování a asymetrické využívání bází má pozitivní vliv na dosah.
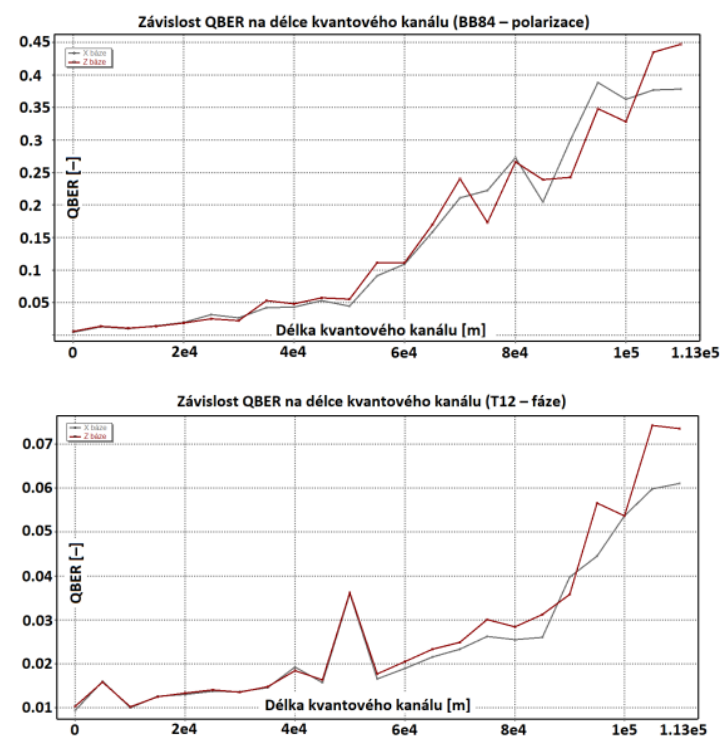

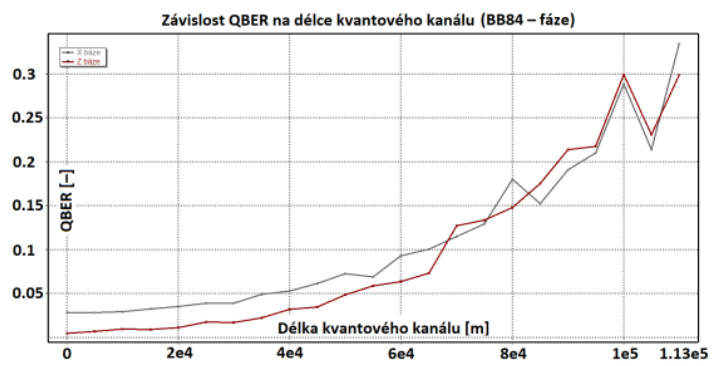

\begin{tabular}{|l|l|l|l|}
\hline \multicolumn{4}{|l|}{ Srovnání protokolů podle QBER } \\
\hline Model & $\mathbf{2 0} \mathbf{~ k m}$ & $\mathbf{6 0} \mathbf{~ k m}$ & $\mathbf{1 1 0} \mathbf{~ k m}$ \\
\hline BB84-P & $4 \%$ & $12 \%$ & $42 \%$ \\
\hline BB84-F & $3 \%$ & $6 \%$ & $32 \%$ \\
\hline T12-F & $1 \%$ & $2 \%$ & $7 \%$ \\
\hline
\end{tabular}

Obrázek 3: Výsledky měření QBER.

\section{ODHALENÍ ODPOSLECHU POMOCÍ QBER}

V následující simulaci už bude vystupovat také odposlouchávající Eva. Eva změří od Alice pocházející fotony v náhodné bázi. Jejich hodnoty následně namoduluje na nové fotony pomocí báze, kterou měřila. Dojde-li při detekci k chybě, je hodnota nového bitu automaticky určena jako 0.

BB84 - POLARIZACE S ODPOSLECHEM

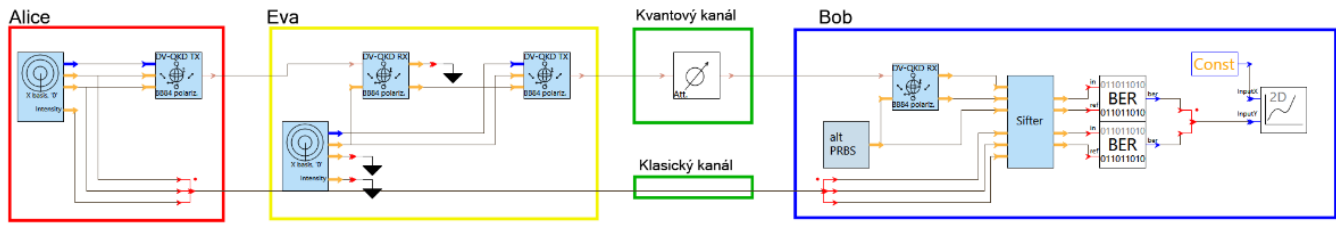

Obrázek 4: Zapojení s odposlouchávající Evou pro protokol BB84-P.

Oproti předchozím měření lze vyčíst prudký nárůst QBER. V ideálním př́ípadě s SPS by měla tvořit cca $25 \%$. Využití WCP stejně jako nedokonalosti zařízení zvyšují QBER až na cca 48 \%. To značí velmi nízkou míru korelace mezi Alicí a Bobem (nulová korelace odpovídá 50 \% QBER). Drtivá většina kvantových signálů tak k Bobovi dorazí poškozená.

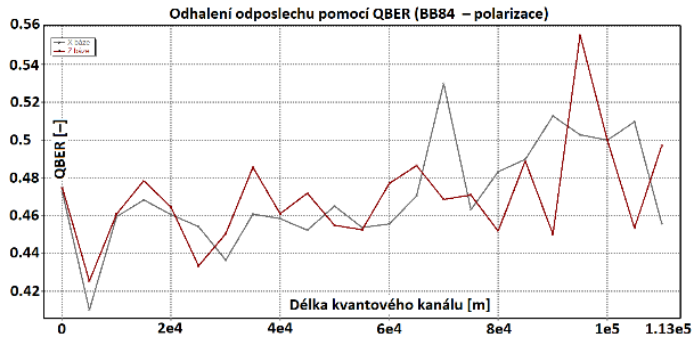

Obrázek 5: Odhalení odposlechu pomocí QBER. 


\section{NÁVRH TESTOVACÍHO QKD POLYGONU}

Pro stavbu vlastního polygonu (QKDN) se počítá s využitím zařízení Clavis3 firmy IDQ. Toto zařízení využívá tzv. COW protokol (Coherent One-way protocol). Obecně se ale předpokládá, že návrh není na QKD protokolu závislý. Pro kompletní šifrovanou komunikaci jsou potřeba tři logické linky. Kvantový kanál pro přenos kvantových signálů, klasický kanál (2 fyzické linky pro duplex), pro výměnu servisních a signálů mezi QKD servery a libovolný kanál pro šifrovanou komunikaci.

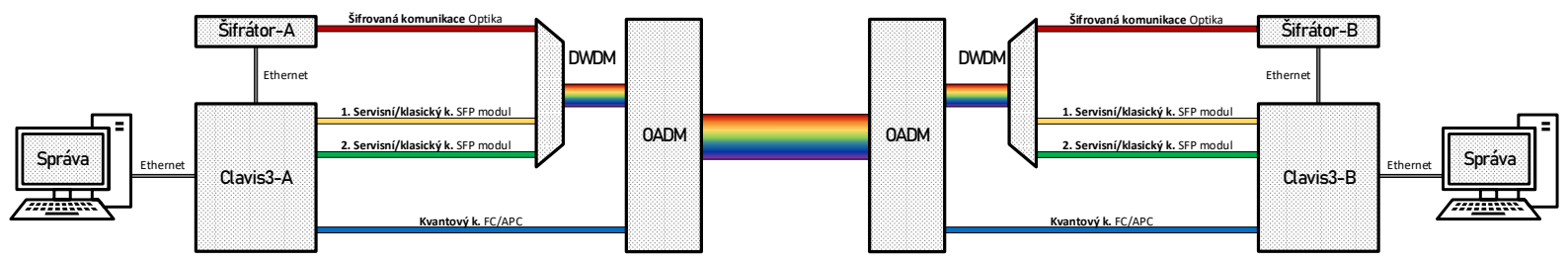

Obrázek 6: Návrh testovacího QKD polygonu s multiplexory.

Návrh počítá s testováním vlivu multiplexorů na kvantové signály. Z tohoto důvodu se plánuje využít OADM s nižším útlumem než u běžných multiplexorů. Nekvantové signály lze cestou obnovit, a tak mohou být agregovány pomocí běžných DWDM. Navržené vlnové délky QKD serveru jsou nastaveny na $\lambda_{k}=1551,72 \mathrm{~nm}$ pro kvantový kanál a $\lambda_{s 1}=1563,047 \mathrm{~nm}$ a $\lambda_{s 2}=1563,863 \mathrm{~nm}$ pro servisní data (C-pásmo). Šifrovaný kanál může mít přidělenu libovolnou vlnovou délku dle potřeby. Rychlost generování klíče je $v=1,4 \mathrm{kbit} / \mathrm{s}$ s maximální dosahem cca $58 \mathrm{~km}$. To odpovídá útlumu $a=14 d B$. Pro správu QKD serveru mohou být dočasně připojeny počítače. [4]

Jakožto testovací šifrátor bylo navrženo open-source řešení QKD in OpenSSL, poskytující L4 datovou ochranu. Tento typ QKDN bývá kvůli připojení bod-bod taktéž nazýván QVPN. Pro komunikaci mezi QKD serverem a šifrátorem je nutné, aby měla obě zařízení jednotné standardizované rozhraní - ETSI Key Delivery API. [5]

\section{ZÁVĚR}

QKD sítě začínají být v současnosti testovány čím dál častěji a současně začínají být nasazovány v ostrém provozu. Př́kladem mohou být testovací sítě DARPA (USA), SwissQuantum (Švýcarsko), mezinárodní evropský projekt SECOQC nebo japonská městská QKDN v Tokiu. V provozu jsou rovněž rozsáhlé integrované čínské páteřní (např. Peking-Šanghaj) a městské (např. Peking, Wuchan, Šanghaj) sítě. V lednu roku 2021 tvořila celková délka vláken čínských sítí cca $4600 \mathrm{~km}$. Kromě nich jsou rovněž testovány free-space (bezdrátové) verze QKD protokolů. Nejznámějším zástupcem je patrně sít' QUESS, vyžívající satelit Mozi/Micius. [6]

\section{REFERENCE}

[1] PIRANDOLA, Stefano, Ulrik ANDERSEN, Leonardo BANCHI, et al. Advances in Quantum Cryptography. Advances in Optics and Photonics [online]. [cit. 2021-03-10]. ISSN 19438206. Dostupné z: doi:10.1364/AOP.361502

[2] PROTOCOLEBB84 [online]. Université de Nice, 2015 [cit. 2021-03-10]. Dostupné z: http://physique.unice.fr/sem6/2014-2015/PagesWeb/PT/Tomographie/?page=bb84

[3] MUGA, Nelson J., Mário F. S. FERREIRA a Armando N. PINTO. QBER Estimation in QKD Systems With Polarization Encoding. Journal of Lightwave Technology [online]. 2011, 29(3), 355-361 [cit. 2021-03-10]. ISSN 0733-8724. Dostupné z: doi:10.1109/JLT.2010.2099643

[4] IDQ [online]. Genève: IDQ, 2020 [cit. 2021-03-10]. Dostupné z: https://www.idquantique.com

[5] RIJSMAN, Bruno. Quantum Key Distribution (QKD) in OpenSSL [online]. 2019 [cit. 202103-10]. Dostupné z: https://brunorijsman.github.io/openssl-qkd/doc/the-etsi-qkd-api.html 